\author{
추청벼 총체 사일리지의 사료가치 및 부위별 In situ 분해율에 관한 연구 \\ 기광석 ${ }^{1} \cdot$ 박수범 $^{1} \cdot$ 임동현 $^{1} \cdot$ 박성민 $^{1} \cdot$ 김상범 ${ }^{1} \cdot$ 권응기 $^{1} \cdot$ 이세영 ${ }^{2} \cdot$ 최기춘 $^{1 *}$ \\ ${ }^{1}$ 농촌진흥청 국립축산과학원, ${ }^{2}$ 천안연암대학
}

\title{
Study on Nutritive Value and In Situ Ruminal Degradability of Whole Crop Rice Silage Prepared Using Chucheongbyeo

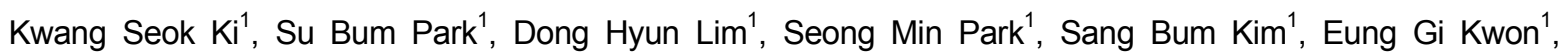 \\ Se Young Lee ${ }^{2}$ and Ki Chon Choi ${ }^{1}$ * \\ ${ }^{1}$ National Institute of Animal Science, RDA, Cheonan 331-808, Korea, \\ ${ }^{2}$ Cheonan Yonam College, Cheonan 330-709, Korea
}

\begin{abstract}
We investigated the nutritive value and ruminal in situ dry matter degradability of whole crop rice silage prepared using Chucheongbyeo (WCRS) as a roughage source for ruminants. The crude protein (7.54\%), acid detergent fiber (29.63\%), neutral detergent fiber (62.98\%), and total digestible nutrient (TDN) (57.88\%) found higher in WCRS than those of rice straw. Manganese content in the WCRS was the highest, followed by carbon, iron, zinc, and copper, but magnesium content was the lowest. Glutamic acid content in WCRS was the highest, followed by leucine, asparagine, alanine, valine, arginine, and methionine content was the lowest. We examined ruminal in situ digestibility from total whole crop rice (TWCR), rice husks containing rice (RHR), whole crop rice except RHR (WER), and husked grain (HG) for 3, 6, 12, 24, and 48 hours. Ruminal in situ digestibility in the HG was the highest, followed by RHR, TWCR, and WER. Therefore, we suggest that ruminal in situ degradability was influenced by parts of whole crop rice, and the content of manganese and glutamic acid were the highest in WCRS.
\end{abstract}

(Key words : Whole crop rice silage, Nutritive value, Amino acid, Digestibility)

\section{I. 서 론}

소를 사육하는 양축가에게 조사료의 안정적인 공급은 매 우 중요하다. 조사료는 반추가축의 귀중한 사료로서 매일 적정량을 급여하여야 하나, 우리나라는 조사료 생산 기반 이 취약하여 양질 조사료를 충분히 생산하지 못하고 볏짚 에 의존하거나 또는 외국에서 수입하여 충당하고 있는 실 정이다.

최근 국외에서는 바이오 에너지의 생산·이용에 대한 영 향으로 곡물가격이 급등하고 국내에서는 쌀 생산성 향상과 소비량 감소와 더불어 수입 쌀의 증가로 인하여 매년 쌀의 재고가 증가되고 있으며, WTO 농업협정으로 최소시장접근 $(\mathrm{MMA})$ 에 의한 쌀 시장 개방 폭이 점차 확대되고 있는 추 세이다.

지금까지 논은 벼를 중심으로 한 주곡생산지로 활용되었
으나 지속적인 쌀 수요 감소에 따라 논을 벼 재배 이외의 목적, 즉 조사료 생산을 위해 활용하고자 하는 노력의 연 구가 진행되었다(Ji et al., 2010; Kim et al., 2011; Ji et al., 2009; Kim et al., 2007b). 그러나 쌀은 우리나라 농업 의 기간작목으로 농가의 중요한 소득원이며 이를 재배하는 논은 홍수조절, 수질정화, 토양보전 등 공익적 기능이 매우 크기 때문에 조사료 재배지로서 논을 활용하기에는 많은 제약이 따르고 있는 실정이다.

현재 우리나라에는 약 1,200 천 ha 정도 논이 있으며 이 중 1,050 천 ha 정도가 벼 재배용으로 이용되고 있는데, 이 중에서 답리작으로 작물재배가 가능한 논 면적은 885 천 ha (논면적의 $70 \%$ )로 추산되며 향후 10 년간 250 천 ha의 휴경 논 발생이 예상됨에 따라 논을 이용한 양질 조사료 생산이 용 기술 확립 및 정책적 지원은 중요한 이슈가 될 수 있 다. 그러나 우리나라의 경우 벼 재배기간에 비가 많이 오

* Corresponding author: Ki Choon Choi, National Institute of Animal Science, RDA, Cheonan 331-808, Korea. Tel: +82-41-580-6755, Fax: +82-41-580-6779, E-mail: choiwh@korea.kr 
는 지역에서는 논에 벼를 대체할 수 있는 작물이 극히 드 물기 때문에 벼 대체 작물을 선발하는 것은 어려운 실정이 다. 이와 같이 벼 대체 작물의 선정이 어려운 지역에서 유 휴 논의 발생을 방지하면서 양질 조사료를 생산하면 많은 양의 수입조사료 (852천 톤, 2011년 기준)를 대체하는 효과 와 더불어 조사료 자급률을 향상시킬 수 있는 기회로 인식 되어 벼의 조사료화에 대한 연구가 다양하게 시도되었다 (Choi et al., 2010; Kim et al., 2009; Lim et al., 2007; Kim et al., 2007a). 그러나 총체 벼는 볏짚과는 달리 영양소가 풍부한 줄기와 잎 그리고 전분을 포함 낟알과 왕겨 등으로 구성되는데 일부 농가에서는 총체 벼가 가축 위내에서 충 분히 영양소원으로 이용되지 못하고 일부 낟알을 포함한 왕겨가 그대로 배설되어 조사료원으로써 사료가치에 의문 을 제기하고 있는 상황이다. 특히, 총체 벼를 조사료원으로 활성화시키기 위해서는 부위별 소화율의 제시는 중요한 요 인으로 생각된다.

따라서 본 연구는 총체 벼를 조사료 자원으로 활용하기 위해 추청벼 총체 사일리지를 조제하였을 때 추청벼 총체 사일리지의 사료가치 및 부위별 소화율을 조사하여 추청벼 총체 사일리지의 이용성을 검정하기 위해서 수행하였다.

\section{ㅍ. 재료 및 방법}

본 시험에 공시된 벼 품종은 중부지방에서 가장 많이 재 배되는 추청벼를 이용하였으며, 파종은 2012년 4월 25일 육묘상자에 파종하고 5 월 25 일 $30 \times 15 \mathrm{~cm}$ 간격으로 기계 이앙을 하였다. 시비량은 질소-인산-칼리를 150-50-70 $\mathrm{kg} / \mathrm{ha}$ 로 하여 질소질 비료는 밑거름-가지칠 비료-이삭비 료-알비료를 각각 $50-20-20-10 \%$ 비율로 분시 하였으며, 인산은 전량 기비로 사용하였으며 칼리는 기비-이삭거름 을 $70-30 \%$ 로 분시 하였다.

추청벼 총체 사일리지는 황숙기에 수확하여 제조하였는 데, 즉 총체 벼는 집초기를 이용하여 베일링 전에 집초 하 였으며 지름 $120 \mathrm{~cm}$, 폭 $120 \mathrm{~cm}$ 규격의 대형 라운드베일 $(\mathrm{F}$ 21; FORT \& PEGORARO Co. Italy)을 이용하여 베일링 하였다. 그리고 베일링 된 총체 벼는 보관 장소로 즉시 이 동하여 wrapper (FORT \& PEGORARO Co. Italy)를 이용하 여 4겹의 비닐을 감아 보관하였다. 총체 벼 사일리지 제조 후 약 2 개월 된 사일리지에서 사일리지 시료채취기 (Uni-Forage Sampler; STAR QUALITY SAMPLER Co. Canada)로 약 $500 \mathrm{~g}$ 을 채취하여 총체 벼, 낟알을 제거한 줄 기, 왕겨를 전부 제거한 낟알(쌀), 왕겨 등으로 분류하였다. 분류 후 바로 $65^{\circ} \mathrm{C}$ 순환식 송풍 건조기 내에서 72 시간 이
상 건조시킨 다음 분쇄하여 시료의 조단백질, 조지방, 조섬 유는 AOAC법 (1990)에 의해 분석하였고, neutral detergent fiber (NDF) 및 acid detergent fiber (ADF) 함량은 Goering and Van soest법 (1970)으로 분석하였다. 가소화영양소 총량 (total digestible nutrients, $\mathrm{TDN})$ 은 $88.9-(\mathrm{ADF} \% * 0.79)$ 에 의 해서 산출하였다.

사일리지 부위별 분해율은 반추위에 누관 (cannulae)이 장 착된 체중 $620 \mathrm{~kg}$ Holstein 종 건유우 3두를 공시하여 이용 하였다. 시료의 분해율은 약 $5 \mathrm{~g}$ 의 시료를 칭량하여 nylon bag에 넣고, 나이론 끈으로 bag의 끝에서 $2.5 \mathrm{~cm}$ 를 묶은 다 음, 큰 그물망에 모아서 따뜻한 물에 약 1 분정도 수침을 하였다. 그 다음 canula의 뚜껑을 열고 nylon bag이 든 그 물망을 넣은 뒤 canula의 뚜껑을 닫아 실험을 수행하였다. 배양 시간대별로 canula의 뚜껑을 열고 회수한 nylon bag을 즉시 얼음물에 침지하였다. 0시간대는 nylon bag 시료를 반 추의 canula에 넣지 않고 분석하였으며, 회수한 nylon bag 을 맑은 물이 나올 때까지 30 분 동안 세척하였다. 그 다음 에 $70^{\circ} \mathrm{C}$ 건조기에서 48 시간 건조한 후 무게를 칭량하였다. 시료의 무기물 분석은 Inductively coupled plasma(ICP) spectroscopy (ICPS 7510, Shimadzu, Kyoto, JP)를 이용하여 측정하였다. 그리고 아미노산 함량은 시료 $5 \mathrm{~g}$ 과 $6 \mathrm{~N} \mathrm{HCl}$ $40 \mathrm{~mL}$ 를 둥근 플라스크에 넣고 혼합한 다음 $110^{\circ} \mathrm{C}$ 에서 24 시간 동안 질소가스를 주입하여 가수분해하였다. 그리고 염산을 $50^{\circ} \mathrm{C}$ 에서 증발·농축시킨 다음 농축시료는 $0.2 \mathrm{~N}$ sodium citrate buffer $(\mathrm{pH}$ 2.2) $50 \mathrm{~mL}$ 를 넣어 희석시키고 여 과지 $(0.45 \mu \mathrm{m})$ 로 여과하였다. 여과한 시료 $(30 \mu \mathrm{L})$ 는 아미노 산 분석기 (Model 835, Hitachi, Japan)를 이용하여 분석하 였다.

\section{III. 결과 및 고찰}

\section{1. 추청벼 총체 사일리지의 사료가치}

총체 벼 사일리지의 성분 함량은 Table 1 에서 보는 바와 같이 조단백질 함량은 $7.54 \%$, 조지방 $2.44 \%, \mathrm{NDF} 62.98 \%$ 및 $\mathrm{ADF} 29.63 \%$ 로, 일반 볏짚에 비하여 유의적으로 높은 사료가치를 보였다. 특히 총체 벼 원형곤포 사일리지의 $\mathrm{TDN}$ 함량도 볏짚에 비해 현저하게 높은 수준을 보였는데, 이는 총체 벼에는 알곡이 포함되어 있기 때문이다.

\section{2. 추청벼 총체 사일리지 내 무기물 함량}

추청벼 총체 사일리지의 무기물 분석결과는 Table 2에서 
Table 1. Chemical composition of whole crop rice silage on Chucheongbyeo

\begin{tabular}{ccccccc}
\hline \multirow{2}{*}{ Items } & $\mathrm{CP}^{3)}$ & $\mathrm{ADF}^{4)}$ & $\mathrm{NDF}^{5)}$ & $\begin{array}{c}\text { C. fat } \\
(\%)\end{array}$ & $\begin{array}{c}\text { C. fiber } \\
(\%)\end{array}$ & $\begin{array}{c}\mathrm{TDN}^{6} \\
(\%)\end{array}$ \\
\hline \hline $\mathrm{WCB}^{1)}$ & $7.54 \mathrm{a}$ & $29.63 \mathrm{~b}$ & $62.98 \mathrm{~b}$ & $2.44 \mathrm{a}$ & $24.53 \mathrm{~b}$ & $57.88 \mathrm{a}$ \\
$\mathrm{RS}^{2)}$ & $5.07 \mathrm{~b}$ & $51.02 \mathrm{a}$ & $75.41 \mathrm{a}$ & $1.99 \mathrm{~b}$ & $32.04 \mathrm{a}$ & $43.66 \mathrm{~b}$ \\
\hline
\end{tabular}

${ }^{1)}$ WCB: Whole crop rice silage, ${ }^{2)}$ RS: Rice straw, ${ }^{3)}$ Crude protein, ${ }^{4)}$ ADF: Acid detergent fiber, ${ }^{5)}$ NDF: Neutral detergent fiber, ${ }^{6}$ TDN: Total digestible nutrient,

${ }^{\mathrm{a}, \mathrm{b}}$ : Different letters within a column represent significant differences $(\mathrm{p}<0.05)$.

Table 2. Contents of amino acid and inorganic matter in whole crop rice silage on Chucheongbyeo

\begin{tabular}{cc|cc}
\hline Amino acids & $\begin{array}{c}\text { Content } \\
(\%)\end{array}$ & $\begin{array}{c}\text { Inorganic } \\
\text { matter }\end{array}$ & $\begin{array}{c}\text { Content } \\
(\mathrm{mg} / \mathrm{g})\end{array}$ \\
\hline \hline Cystine & 0.215 & $\mathrm{Ca}$ & 0.18 \\
Methionine & 0.127 & $\mathrm{P}$ & 0.22 \\
Asparagine & 0.525 & $\mathrm{Na}$ & 0.36 \\
Threonine & 0.270 & $\mathrm{Mg}$ & 0.06 \\
Serine & 0.306 & $\mathrm{Fe}$ & 22.10 \\
Glutamic acid & 0.921 & $\mathrm{Mn}$ & 450.78 \\
Glycine & 0.360 & $\mathrm{Zn}$ & 5.32 \\
Alanine & 0.514 & $\mathrm{Cu}$ & 2.91 \\
Valine & 0.384 & $\mathrm{C}$ & 41.09 \\
Isoleucine & 0.261 & $\mathrm{~N}$ & 1.21 \\
Leucine & 0.528 & $\mathrm{~S}$ & 0.12 \\
Tyrosine & 0.214 & $\mathrm{Cr}$ & 0.61 \\
Phenylalanine & 0.369 & $\mathrm{~F}$ & 0 \\
Lysine & 0.321 & $\mathrm{~Pb}$ & 2.11 \\
Histidine & 0.209 & $\mathrm{Cd}$ & 0 \\
Arginine & 0.380 & $\mathrm{As}$ & 0.25 \\
Proline & 0.308 & $\mathrm{Hg}$ & 0.02 \\
\hline
\end{tabular}

보는 바와 같다. 총체 벼 사일리지의 무기물 함량은 망간 이 가장 높았으며 탄소, 철, 아연, 구리 등 순으로 나타났 다. 그리고 망간의 함량은 마그네슘 (7,513배), 황 (3,757배), 칼슘 (2,504배), 인 (2,049배), 비소 (1,803배), 나트륨 $(1,252$ 배) 등 보다 높은 경향을 보였다. 또한 불소, 카드뮴, 수은 등은 검출이 되지 않았다. 이상의 결과에서 보는 바와 같 이 가축에게 중요한 무기물이 다량 함유되어 있음에도 불 구하고 이제까지 조사료 내 무기물 함량에 대한 조사가 거 의 이루어지지 않고 있는 실정이다(Jeon et al., 2012; Hwang et. al., 2009). 무기물은 가축대사 질환과도 밀접한 관련 (Goff et al., 2007)이 있기 때문에 시비, 수확시기, 가 공방법 등 다양한 측면에서 무기물 함량 변화에 대한 접근 이 이루어져야 할 것으로 생각된다.
3. 총체 벼 사일리지의 아미노산 함량

Table 2에서 보는 바와 같이, 추청벼 총체 사일리지의 아미노산 조성은 glutamic acid 함량이 가장 높았으며 leucine, asparagine, alanine, valine, arginine 순으로 나타났다. 그리 고 glutamic acid의 함량은 methionine (7.3배), tyrosine과 cystine (4.3배), isoleucine과 threonine (3.5배) 등 보다 높은 경향을 보였다. 이는 Choi et al. (2012)이 보고한 논문에서 도 백수 벼의 아미노산 함량 변화와 비슷한 수준을 보였 다. 또한 Choi et al. (2012)은 glutamic acid의 함량이 가장 높고 methionine 및 cystine 함량이 가장 낮았다고 하였는데 본 연구에서도 비슷한 양상을 보였다.

\section{4. 총체 벼 사일리지 부위별 반추위내 소화율}

반추위에 누관 (cannulae)이 장착된 체중 $620 \mathrm{~kg}$ Holstein 건유우 3 두를 공시하여 총체 벼 사일리지 부위별 반추위내 분해율을 조사한 결과는 Table 3 과 같다. 총체 벼의 경우 0 시간대부터 3 시간대까지는 약 $2 \%$ 정도의 분해를 보이다가 6 시간이 경과됨에 따라 약 $20 \%$ 정도 분해되었고 24 시간이 지나면서 약 $30 \%$ 이상의 분해율을 보였다. 그리고 낟알을 제거한 줄기의 경우는 0 시간대부터 6 시간대까지 약 $3 \%$ 정 도의 분해를 보이다가 12 시간이 경과됨에 따라 약 $10 \%$ 정 도 분해되었고 24 시간이 지나면서 약 $15 \%$ 이상의 분해율을 보였다. 왕겨를 포함한 낟알은 0 시간대부터 3 시간대까지 약 $10 \%$ 정도의 분해를 보이다가 12 시간이 경과됨에 따라 약 $35 \%$ 정도 분해되었고 24 시간이 지나면서 약 $77 \%$ 이상 의 분해율을 보였다. 또한 쌀의 경우는 0 시간대부터 3 시간 대까지 약 $30 \%$ 정도의 분해를 보이다가 12 시간이 경과됨 에 따라 약 $50 \%$ 정도 분해되었고 24 시간이 지나면서 약 $98 \%$ 이상의 분해율을 보였다.

이상의 결과에서 보는 바와 같이 왕겨를 포함한 낟알의 경우 반추위 내에서 분해율이 매우 낮았는데 이는 왕겨가 반추위내에서 소화가 거의 이루어지지 않는다는 것을 의미 
Ki et al. ; Nutritive Value of Whole Crop Rice Silage on Chucheongbyeo

Table 3. Digestibility of various samples collected from whole crop rice silage on Chucheongbyeo

\begin{tabular}{ccccc}
\hline Incubation time (hr) & $\mathrm{WCR}^{1)}$ & $\mathrm{WER}^{2)}$ & $\mathrm{RHR}^{3)}$ & $\mathrm{HG}^{4)}$ \\
\hline \hline 0 & 22.54 & 22.31 & 14.44 & 12.36 \\
3 & 24.32 & 25.36 & 25.89 & 28.98 \\
6 & 42.60 & 27.14 & 38.73 & 51.20 \\
12 & 42.62 & 34.21 & 49.85 & 68.62 \\
24 & 54.63 & 39.13 & 77.25 & 97.60 \\
48 & 63.34 & 41.23 & 84.18 & 97.78 \\
\hline
\end{tabular}

${ }^{1)}$ WCB: whole crop rice silage, ${ }^{2)}$ WER: Whole crop rice except RHR, ${ }^{3)}$ RHR: Rice husks containing rice, ${ }^{4)}$ HG: Husked grain.

한다. 따라서 총체 벼의 소화율은 왕겨에 의해 영향을 받 음을 알 수 있었으며 왕겨의 소화를 가능하도록 하는 사일 리지 제조 기법의 개발이 필요할 뿐만 아니라 총체 벼 사 일리지의 이용성을 증진시킬 수 있는 기술개발에 관한 연 구가 지속적으로 이루어져야 할 것으로 생각된다.

$$
\text { IV. 요 약 }
$$

본 연구는 추청벼를 이용하여 총체 벼 사일리지를 조제 하였을 때 총체 벼 사일리지의 사료가치 및 부위별 소화율 을 조사하여 총체 벼의 이용성을 검정하기 위하여 수행되 었다. 총체 벼 사일리지의 무기물 함량은 망간이 가장 높 았으며 탄소, 철, 아연, 구리 등 순으로 나타났다. 그리고 마그네슘 함량이 가장 낮게 나타났다. 추청벼 총체 사일리 지의 아미노산은 glutamic acid 함량이 가장 높았으며 leucine, asparagine, alanine, valine, arginine 순으로 나타났 다. 그리고 methionine 함량이 가장 낮았다. 추청벼 총체 사일리지 부위 (총체 벼, 낟알을 제거한 줄기, 왕겨를 포함 한 낟알, 쌀)에 따른 시간별 반추위내 건물 소화율은 쌀이 가장 높았으며 왕겨를 포함한 낟알, 총체 벼, 낟알을 제거 한 줄기 등 순으로 나타났다. 따라서 본 연구에서는 추청 벼 총체 사일리지 소화율은 부위에 따라 약간의 차이를 보 였으며 무기물 중 망간 그리고 아미노산 중 glutamic acid 가 가장 높은 함량을 보였다.

\section{REFERENCES}

AOAC. 1990. Official methods of analysis (15th ed.). Association of Offical Analytical Chemists, Washington, DC.

Choi, C.W., Chung, E.S., Hong, S.K., Oh, Y.K., Kim, J.G. and Lee,

S.C. 2010. Feed evaluation of whole crop rice silage harvested at different mature stages in hanwoo steers using In Situ technique.
Journal of the Korean Society of Grassland and Forage Science. 30:143-150.

Choi, K.C., Ryu, J.H., Jung, M.W., Park, H.S., Kim, C.M., Lim, Y.C., Kim, D.H., Choi, K.J. and Kim, W.H. 2012. Changes of amino acid contents in white panicled rice (Oryza sativa L.). Journal of the Korean Society of Grassland and Forage Science. 32:93-100.

Goff, J.P., Brummer, E.C., Henning, S.J., Doorenbos, R.K. and Horst, R.L. 2007. Effect of application of ammonium chloride and calcium chloride on alfalfa cation-anion content and yield. Journal of Dairy Science. 90:5159-64.

Goering, H.K. and Van Soest, P.J. 1970. Forage fiber analysis. Agic. Handbook 379, U. S. Gov. Print. Office, Washington, DC.

Hwang, K.J., Park, H.S., Park, N.G., Jeong, H.Y., Ko, M.S. Kim, M.C., Song, S.T. and Kim, D.W. 2009. Effect of cattle manure application on mineral contents of grazing pasture. Journal of the Korean Society of Grassland and Forage Science. 29:37-42.

Jeon, B.T. Moon, S.H. and Lee, S.M. 2012. A comparative studies on the growth characteristics and feed components of sorghum $\times$ sudangrass hybrids at paddy field Cultivation. Journal of the Korean Society of Grassland and Forage Science. 32:29-38.

Ji, H.C., Kim, W.H., Kim, K.Y., Lee, S.H., Yoon, S.H. and Lim, Y.C. 2009. Effect of different drained conditions on growth, forage production and quality of silage corn at paddy field. Journal of the Korean Society of Grassland and Forage Science. 29:329-336.

Ji, H.C., Lee, S.H., Yoon, S.H., Kim, W.H. and Lim, Y.C. 2010. Growth, forage production and quality of sorghum, sorghum $\times$ sudangrass and sudangrass hybrids at paddy field in middle region of Korea. Journal of the Korean Society of Grassland and Forage Science. 30:9-14.

Kim, J.G., Chung, E.S., Ham, J.S., Seo, S., Kim, M.J., Yoon, S.H. and Lim, Y.C. 2007a. Effect of growth stage and variety on the 
yield and quality of whole crop rice. Journal of the Korean Society of Grassland and Forage Science. 27:1-8.

Kim, J.G., Chung, E.S., Lee. J.K., Lim, Y.C., Yoon, S.H. and Kim, M.J. 2009. Comparison of yield and quality of direct-seeded whole crop rice. Journal of the Korean Society of Grassland and Forage Science. 29:25-30.

Kim, W.H., Kim, K.Y., Jung, M.W., Ji, H.C., Lim, Y.C., Seo, S., Kim, J.D., Yoon., B.K. and Lee, H.W. 2011. Dry matter yield and forage quality at mixture of annual legumes and Italian ryegrass on paddy field. Journal of the Korean Society of Grassland and Forage Science. 31:33-38.
Kim, W.H., Seo, S., Lim, Y.C., Shin J.S., Sung, B.R., Ji, H.C., Lee, S.J. and Park, T.I. 2007b. Selection of promising barley cultivar for silage at paddy field of Honam Region. Journal of the Korean Society of Grassland and Forage Science. 27:161-166.

Lim, Y.C., Yoon, S.H., Jung, M.W., Kim, W.H., Kim, J.G., Lee, J.K., Seo, S., Park, N.G. and Yook, W.B. 2007. Effect of livestock manure application on the productivity of whole crop rice, feed value and soil fertility. Journal of the Korean Society of Grassland and Forage Science. 27:287-296.

(Received July 12, 2013/Revised August 6, 2013/Accepted August $15,2013)$ 